\title{
Allophonic mode of speech perception in Dutch children at risk for dyslexia: A longitudinal study
}

\author{
M.W. Noordenbos ${ }^{\mathrm{a}, *}$, E. Segers ${ }^{\mathrm{a}}$, W. Serniclaes ${ }^{\mathrm{b}, \mathrm{c}}$, H. Mitterer $^{\mathrm{d}}$, L. Verhoeven ${ }^{\mathrm{a}}$ \\ a Behavioural Science Institute, Radboud University Nijmegen, The Netherlands \\ ${ }^{\mathrm{b}}$ CNRS, France \\ ${ }^{\mathrm{c}}$ Laboratoire de Psychologie de la Perception, Université Paris Descartes, France \\ ${ }^{\mathrm{d}}$ Max Planck Institute for Psycholinguistics, Nijmegen, The Netherlands
}

\section{A R T I C L E I N F O}

\section{Article history:}

Received 22 December 2011

Received in revised form 6 March 2012

Accepted 6 March 2012

Available online

\section{Keywords:}

At risk for dyslexia

Speech perception

Allophonic perception

Categorical perception

\begin{abstract}
A B S T R A C T
There is ample evidence that individuals with dyslexia have a phonological deficit. A growing body of research also suggests that individuals with dyslexia have problems with categorical perception, as evidenced by weaker discrimination of between-category differences and better discrimination of within-category differences compared to average readers. Whether the categorical perception problems of individuals with dyslexia are a result of their reading problems or a cause has yet to be determined. Whether the observed perception deficit relates to a more general auditory deficit or is specific to speech also has yet to be determined. To shed more light on these issues, the categorical perception abilities of children at risk for dyslexia and chronological age controls were investigated before and after the onset of formal reading instruction in a longitudinal study. Both identification and discrimination data were collected using identical paradigms for speech and non-speech stimuli. Results showed the children at risk for dyslexia to shift from an allophonic mode of perception in kindergarten to a phonemic mode of perception in first grade, while the control group showed a phonemic mode already in kindergarten. The children at risk for dyslexia thus showed an allophonic perception deficit in kindergarten, which was later suppressed by phonemic perception as a result of formal reading instruction in first grade; allophonic perception in kindergarten can thus be treated as a clinical marker for the possibility of later reading problems.
\end{abstract}

(c) 2012 Elsevier Ltd. All rights reserved.

\section{Introduction}

Learning to read is a complex process which requires children to map graphemes onto their corresponding phonemes to establish stable phonological representations. This mapping of graphemes onto phonemes develops normally in most children. However, about 5\% of children encounter difficulties learning to read despite average or above average intelligence, adequate and effective classroom instruction and good socio-cultural opportunities (Démonet, Taylor, \& Chaix, 2004). The reading difficulties of these children typically persist into adulthood, as characterized by slow and error-prone reading, poor non-word reading and weak spelling. This impairment is referred to as developmental dyslexia or a specific reading disability (Démonet et al., 2004; Snowling, 2000).

Although there is still no consensus on the causes of developmental dyslexia, there is widespread recognition that the majority of individuals with dyslexia show a phonological deficit (Elbro, Nielsen, \& Petersen, 1994; Ramus, 2003; Snowling,

\footnotetext{
* Corresponding author at: Behavioural Science Institute, Radboud University Nijmegen, P.O. Box 9104, 6500 HE Nijmegen, The Netherlands.

E-mail address: m.noordenbos@bsi.ru.nl (M.W. Noordenbos).
} 
2000; Vellutino, Fletcher, Snowling, \& Scanlon, 2004). It is generally assumed that there are three facets of the phonological abilities which are impaired in individuals with dyslexia (Castles \& Coltheart, 2004; Ramus, 2003; Wagner \& Torgesen, 1987). First, their phonological awareness, which refers to conscious access and manipulation of the sound structure of language (e.g., phoneme deletion, spoonerism) is impaired. Second, the process of lexical retrieval or, in other words, the conversion of visual symbols into sound-based representations from long-term memory (e.g., rapid automatic naming of familiar stimuli such as letters or objects) is impaired. And third, verbal short-term memory (vSTM) or the ability to recode and maintain phonological representations in working memory for a short period of time (e.g., digit span or sentence repetition recall) is impaired.

There are two dominant theories to explain the observed phonological deficit in relation to the reading problems of individuals with dyslexia. The first theory is the phonological theory which postulates that the phonological deficit is primary and caused by a genetic factor. This theory states that the nature of the phonological deficit lies in poorly specified phonological representations (Snowling, 2000).

The second theory is the general magnocellular theory, which postulates a more general deficit in the neural pathways involved in the fast transmission and processing of sensory information (Stein, 2001; Stein \& Walsh, 1997). According to this theory, the phonological deficit observed in individuals with dyslexia is secondary to a more basic auditory impairment of the processing of short, rapidly presented, dynamic, changing acoustic stimuli; this general impairment leads to poorly specified phonological representations (Ramus, 2004; Tallal, 1980). Deficits in the detection of acoustic speech cues may thus impair the establishment of stable phonological representations (McBride-Chang, 1995; Studdert-Kennedy, 2002). However, the exact nature of these auditory problems is still debated. There is evidence showing the problems to be specific to speech (e.g., Mody, Studdert-Kennedy, \& Brady, 1997; Serniclaes, SprengerCharolles, Carre, \& Démonet, 2001; White et al., 2006). Other evidence suggests a more general auditory deficit, however (e.g., Tallal, 1980; Vandermosten et al., 2010).

Although most studies find a phonological deficit in individuals with dyslexia, auditory processing is not always impaired in such individuals (Ramus et al., 2003; Rosen, 2003). Auditory deficits are therefore not considered a major cause of dyslexia. However, some studies have shown a subgroup of individuals with dyslexia to have speech perception deficits (Adlard \& Hazan, 1998; Joanisse, Manis, Keating, \& Seidenberg, 2000; Lieberman, Meskill, Chatillon, \& Schupack, 1985; Manis et al., 1997; Ramus et al., 2003). For example, Adlard and Hazan (1998) found speech perception deficits in 30\% of the individuals with dyslexia in their study. Other studies have suggested that only those individuals with dyslexia and low phonemic awareness or additional language impairments will show speech perception deficits (Joanisse et al., 2000; Manis et al., 1997).

Another explanation for the poorly specified phonological representations in dyslexia is provided by Serniclaes (2011) and Serniclaes, Van Heghe, Mousty, Carre, and Sprenger-Charolles (2004), namely that children with dyslexia have an allophonic as opposed to 'phonemic' mode of speech perception. In other words, individuals with dyslexia may maintain the sensitivity to phonemic distinctions which all newborns have, irrelevant of their native language. Newborns have the ability to discriminate almost all of the phonemic contrasts in the world's languages, but this ability is quickly reorganized as the relevance of certain contrasts and irrelevance of other contrasts in the language being acquired becomes apparent (Kuhl, 2004; Werker \& Tees, 1984). According to the allophonic explanation of dyslexia, children with dyslexia maintain the inborn ability with a lack of the development of one-to-one relationships between allophones and letters as a result and thus as the origin of their reading problems (i.e., failure to master the alphabetic principle).

Speech perception abilities are often investigated with paradigms based on categorical perception (CP), which has two main characteristics. First, identification functions exhibit an abrupt change from one phonemic category to another at a certain point (i.e., categorical boundary) along a continuous acoustic feature. Second, discrimination of acoustic differences that straddle the categorical boundary tends to be easier than discrimination of equal acoustic magnitude within categories. According to the original conceptualization of $\mathrm{CP}$, listeners perceive only differences between categories and not, thus, within categories (Liberman, Cooper, Shankweiler, \& Studdert-Kennedy, 1967; Liberman, Harris, Hoffman, \& Griffith, 1957). This strong conceptualization of CP has not stood the test of time, however, as it has become clear that listeners can - on certain tasks - discriminate between stimuli coming from the same category (Schouten, Gerrits, \& Van Hessen, 2003); it has also become clear that listeners sometimes use within-category differences for spoken word recognition (McMurray, Aslin, Tanenhaus, Spivey, \& Subik, 2008). Nevertheless, the discrimination of differences between categories tends to be easier than the discrimination of differences within categories. Given that CP is a matter of relationship between the observed discrimination scores and the scores predicted on the basis of identification, the smaller the difference between the observed and predicted scores the greater the CP (Harnad, 1987; Liberman et al., 1957). Speech cues that have received a great amount of attention in speech perception research are voice-onset-time (VOT; e.g., distinguishing [p] from [b]) and place-of-articulation (e.g., distinguishing [b] from [d]). VOT refers to the temporal relationship between the onset of laryngeal vibrations (i.e., voice) and the release of the vocal tract closure. In the voicing domain, three possible categories across languages have been described, a negative VOT category (i.e., onset of voice before the vocal tract closure release), and two positive VOT categories (onset of voice after the vocal tract closure release), one with short positive VOTs and the other with long positive VOTs (Lisker \& Abramson, 1964). The other speech cue, place-ofarticulation, refers to the location where the airstream is obstructed in the vocal tract when a speech sounds is produced. In the case of stop consonants, the place-of-articulation is defined by fast articulatory movements or fast formant transition. The transition of the second and third formants are especially important for the distinction in place-of-articulation of consonants (Mitterer \& Cutler, 2006). 
A large body of evidence has shown children with dyslexia to exhibit both weaker discrimination across phoneme boundaries and better discrimination within phoneme boundaries than children without dyslexia (Godfrey, Syrdal-Lasky, Millay, \& Knox, 1981; Manis et al., 1997; Serniclaes et al., 2001; Werker \& Tees, 1987). Unfortunately, the evidence is not as straightforward as it appears because the place-of-articulation continua used in these studies and the positive VOT continuum used in the Manis et al. study do not contain well-specified allophonic boundaries. Therefore, in our research, a place-of-articulation continuum with well-specified allophonic boundaries is used to investigate the allophonic mode of speech perception in children at risk for dyslexia with a Dutch linguistic background.

In addition to the observed deficit in the $\mathrm{CP}$ of individuals with dyslexia, various studies have found the slope for the identification functions to be less steep for individuals with dyslexia than for controls (e.g., Chiappe, Chiappe, \& Siegel, 2001; Maassen, Groenen, Crul, Assman-Hulsmans, \& Gabreëls, 2001; Manis et al., 1997; Vandermosten et al., 2010). A shallower slope for the identification function indicates less categorical precision (i.e., sharpness of the category boundary), different from the one in categorical perception, which is a matter of relationship between discrimination and identification irrespective of boundary precision (for further specification see Medina, Hoonhorst, Bogliotti, \& Serniclaes, 2010). The distinction between categorical precision and $\mathrm{CP}$ is important because $\mathrm{CP}$ does not change after about the age of two years while categorical precision develops from early infancy through adolescence (Hazan \& Barrett, 2000; Hoonhorst et al., 2010; Medina et al., 2010).

Straightforward support for the allophonic explanation of dyslexia comes from the study of voicing perception. For stimuli varying along a VOT continuum, French children with dyslexia showed a reduced discrimination peak at the phonemic boundary and an unexpected discrimination peak at an allophonic boundary around $-30 \mathrm{~ms}$ VOT (Bogliotti, Serniclaes, Messaoud-Galusi, \& Sprenger-Charolles, 2008; Serniclaes et al., 2004). Sensitivity to allophonic VOT boundaries located at some -30 and +30 ms VOT has also been found in experiments with infants irrespective of their linguistic backgrounds: from a Spanish background (Lasky, Syrdal-Lasky, \& Klein, 1975); from an English background (Aslin, Pisoni, Hennessy, \& Perey, 1981); and from a French background (Hoonhorst et al., 2009). While these $\pm 30 \mathrm{~ms}$ VOT boundaries are used to separate phonemes in languages with three voicing categories (e.g., Thai: Lisker \& Abramson, 1970), they are not relevant for languages such as Spanish, English or French. In the study by Bogliotti et al., moreover, sensitivity to the $-30 \mathrm{~ms}$ VOT boundary was quite reliably associated with dyslexia (i.e., produced $80 \%$ correct classification). However, sensitivity to the +30 ms VOT boundary was difficult to assess in this particular study because it is so close to the French VOT boundary of $+15 \mathrm{~ms}$. The design of the stimulus continuum is thus of critical importance for the demonstration of allophonic perception.

There is also some counter-evidence for the assumption of an allophonic mode of speech perception as characteristic of dyslexia. In a study with adults, Van Beinum, Schwippert, Been, Van Leeuwen, and Kuijpers (2005) found no evidence for heightened sensitivity to acoustic differences within the same phonemic category among those with dyslexia and therefore suggested that allophonic perception may only be present in children. In another study of the perception of long versus short positive VOT, which is phonemic in Korean but allophonic in French, no over discrimination of the contrast by the French children with dyslexia was found (Ramus \& Szenkovits, 2008).

However, recent neuroimaging data suggest that when individuals with dyslexia do not show heightened sensitivity to acoustic differences within the same phonemic category behaviourally, it might still be present in the form of neural activation. In a PET study of French adults with dyslexia using a ba/da continuum, for example, no behavioural differences were detected while reduced neural activation across the phoneme boundary for those with dyslexia as opposed to no dyslexia was found (Dufor, Serniclaes, Sprenger-Charolles, \& Démonet, 2009). This study also showed discrimination of between-category pairs to be related to enhanced activation in the left inferior premotor cortex in non-dyslexic adults while discrimination of within-category pairs was related to the same form of activation in dyslexic adults (Dufor et al., 2009). This suggests that activation in this region, which is close to Broca's area, relates to phonemic perception in average readers and allophonic perception in dyslexic readers.

In sum, there is a growing evidence that individuals with dyslexia may have an allophonic mode of speech perception. And while a growing body of evidence concerns the identification of an allophonic mode of perception among children at risk for dyslexia, little is known about the speech perception abilities of pre-reading (i.e., kindergarten) children at risk for dyslexia. A heightened allophonic sensitivity in individuals diagnosed with dyslexia does not - in and of itself demonstrate a possible causal relationship between speech perception problems and dyslexia (Bogliotti et al., 2008; Dufor et al., 2009; Serniclaes et al., 2004). The presence of an allophonic mode of speech perception in pre-reading children at risk for dyslexia, would suggest that the allophonic mode of speech perception may be a cause and not an effect of later reading problems. Furthermore, the impact of formal reading instruction on the persistence of such speech perception problems is also not clear.

In the present study, we therefore investigated auditory perception problems in Dutch children at risk for dyslexia before and after the receipt of formal reading instruction. In a longitudinal study, we examined the speech perception of children in kindergarten (i.e., just before the initiation of formal reading instruction) to see if children at risk for dyslexia indeed show auditory perception problems including an allophonic mode of speech perception. One year later, the same children were again examined to gain insight into the effects of formal reading instruction on the persistence or nonpersistance of any speech perceptions problems. The same paradigms were used in speech and non-speech tasks with stimuli which were comparable with regard to acoustic complexity. Given that CP depends on the relationship between discrimination and identification, we collected both discrimination and identification data and assumed that the smaller the difference between the observed discrimination score and the score predicted on the basis of identification, the greater the CP (Harnad, 1987; 
Liberman et al., 1957). Both discrimination and identification tasks were used because of their differential complexity. Discrimination tasks can be assumed to place greater demands on working memory than identification tasks because of the more fine-grained discriminations required, and it is suggested that discrimination tasks are thus more sensitive to potential differences between groups than identification tasks (Manis et al., 1997).

The specific research questions were as follows:

1. Do kindergarten children at risk for dyslexia show an auditory deficit and, if so, is the deficit specific to speech or more general?

2. Do kindergarten children at risk for dyslexia show an allophonic or phonemic mode of perception for place-of-articulation information?

3. Does the onset of formal reading instruction influence the mode of speech perception in control versus children at risk for dyslexia?

In order to answer the first question, we compared the identification and discrimination of speech and non-speech stimuli. If the at-risk children show a general auditory deficit, then the perception of both types of stimuli should be impaired. Conversely, if the at-risk children show a speech-specific auditory deficit, then the perception of the nonspeech stimuli should not differ for the control versus at-risk children. In order to answer the second question, we used a place-of-articulation continuum with clear allophonic boundaries, which is in contrast to previous studies. We expected the children at risk for dyslexia to show an allophonic mode of speech perception and thus be more sensitive to differences within a phoneme category than the control children. In order to answer the third question, we compared the children's later speech perception. If the children indeed show an allophonic mode of speech perception in kindergarten, then the start of formal reading instruction in first grade is not expected to influence their speech perception because the allophonic mode of speech perception has been found to persist in older school-aged children diagnosed with dyslexia.

\section{Method}

\subsection{Participants}

Eighty-three children attending kindergarten in the Netherlands ${ }^{1}$ participated in this study. The children were divided into two groups: children with dyslexic relatives or the at-risk group and children without dyslexic relatives or the control group. The control children were recruited from the same schools as the at-risk children in order to control for the educational environment. At the time of inclusion, all of the children were in the year before formal reading instruction is initiated. The children were all born in the Netherlands and native Dutch speakers. The at-risk children were selected for inclusion in this study based on the presence of at least one first degree relative diagnosed with dyslexia (cf. Kuijpers et al., 2003). Since dyslexia runs strongly in families, children with a first degree relative with dyslexia have a high risk of developing reading problems. About $40-60 \%$ of the offspring of parents with dyslexia is expected to develop reading problems (Grigorenko, 2001).

The initial at-risk group consisted of 41 children between 64 and 81 months ( 19 girls and 22 boys, $M_{\text {age }}=71.6$ months). All children in the at-risk group had a parent with diagnosed dyslexia or reading problems. As an extra control for the reading problems of the parents, they were asked to perform three standardized reading tasks: (1) the one-minute-reading test which requires respondents to read as many words as quickly and accurately as possible within 1 min (Brus \& Voeten, 1999); (2) a non-word reading test which requires respondents to read as many non-words as quickly and accurately as possible within 2 min (Van den Bos, Lutje Spelberg, Scheepstra, \& De Vries, 1994); and (3) the subtest for Verbal Competence from the Dutch version of the Wechsler Adult Intelligence Scale (WAIS, Uterwijk, 2000). If parents performed too high on these tasks, the child was excluded from our study. The parents thus had to meet one of the following criteria for their child to be included in our study (Kuijpers et al., 2003): (i) score on the one-minute-reading test in the lowest 10\% (i.e., raw score $\leq 70$ ); (ii) score on the non-word reading test in the lowest $10 \%$ (i.e., raw score $\leq 55$ ); (iii) both scores on the oneminute-reading and the non-word reading tests in the lowest $25 \%$ (i.e., raw score one-minute-reading $\leq 80$ and raw score non-word reading $\leq 74$ ); or (iv) difference in percentiles between Verbal Competence and one-minute-reading or nonword tests above $60 \%$.

These criteria were applied successively, in the sense that criteria iii and iv were only considered when criteria i and ii were not met. The parents of six children in the initial at-risk group did not fulfil the above criteria and their children were thus excluded. An additional four children (two at-risk and two control) were referred to special education schools during the study and therefore excluded from further analysis. The remaining at-risk group of kindergarten children consisted of 33 children between 64 and 80 months of age ( 17 girls and 16 boys, $M_{a g e}=71.0$ months). The initial control group with no family history of reading problems consisted of 40 children between 60 and 81 months of age ( 21 girls and 19 boys, $M_{\text {age }}=71.4$ months). Both groups were comparable in age and nonverbal intelligence as shown in Table 1.

\footnotetext{
${ }^{1}$ Note that Dutch children go to school from an age of four. Reading instructions starts around the age of six. In line with international conventions, we thus adopted kindergarten (i.e., the second year of Dutch school) and first grade (i.e., the third year of Dutch school) as our measurement times.
} 
Table 1

Means and group differences according to age, nonverbal memory, vSTM, RAN, PA and reading skills for children at risk for dyslexia versus control children.

\begin{tabular}{|c|c|c|c|c|c|c|}
\hline & \multicolumn{3}{|l|}{ Kindergarten } & \multicolumn{3}{|l|}{ First grade } \\
\hline & Control $(n=40)$ & At-risk $(n=33)$ & & Control $(n=38)$ & At-risk $(n=32)$ & \\
\hline & $M(S D)$ & $M(S D)$ & $d$ & $M(S D)$ & $M(S D)$ & $d$ \\
\hline Age (months) & $71.38(4.19)$ & $71.00(3.61)$ & 0.10 & $83.61(4.11)$ & 83.09 (3.63) & 0.13 \\
\hline Raven & $6.67(2.06)$ & $6.53(1.97)$ & 0.07 & & & \\
\hline vSTM & $15.23(4.93)$ & $13.81(3.92)$ & 0.32 & $16.76(4.61)$ & $13.59(5.25)^{* *}$ & 0.64 \\
\hline RAN & $20.54(4.45)$ & $17.79(4.59)^{*}$ & 0.61 & $45.47(7.82)$ & $40.59(8.72)^{*}$ & 0.59 \\
\hline PA & $42.10(8.08)$ & $35.69(9.41)^{* * *}$ & 0.73 & $39.58(3.53)$ & $37.75(3.37)^{*}$ & 0.53 \\
\hline Word reading & & & & $69.32(35.03)$ & $37.22(14.11)^{* * * *}$ & 1.20 \\
\hline Non-word reading & & & & $10.34(2.30)$ & $7.84(1.76)^{* * *}$ & 1.22 \\
\hline
\end{tabular}

Note. vSTM = verbal Short-Term Memory; RAN = Rapid Automatic Naming; PA = Phonological Awareness .

* $p<.05$.

** $p<.01$.

*** $p<.001$

\subsection{Measurements}

\subsubsection{Kindergarten nonverbal intelligence}

Nonverbal intelligence was assessed using the Raven Coloured Progressive Matrices (Raven, 1965). This task consists of 36 visual patterns of increasing difficulty. In each trial, a visual pattern is presented with a missing piece of the pattern. The task of the child is then to select the missing piece from six alternatives. Raw scores were converted into standard scores, ranging from .5 to $9.5(M=5 ; S D=2)$, using Dutch norms (Van Bon, 1986).

\subsubsection{Kindergarten lexical retrieval}

Naming speed was assessed using Rapid Automatic Naming tasks (RAN: Van den Bos \& Lutje Spelberg, 2007; Van den Bos, Zijlstra, \& Spelberg, 2002) for two cards containing different types of stimuli each: objects and colours. The card with objects consists of pictures of five familiar objects: boom ('tree'), eend ('duck'), stoel ('chair'), schaar ('scissors') and fiets ('bicycle'). The card with colours consists of small rectangles of black, blue, red, yellow and green. The objects or colours are represented on a card consisting of 50 items listed randomly in five columns. The child must name the stimuli as fast and accurately as possible. The time to complete the 50 items of each type is measured and converted into standard scores. Performance on the two tasks correlated highly $(r(72)=.62, p<.001)$. The scores on the two tasks were therefore summed to produce a raw RAN score which fulfilled the assumption of normality.

\subsubsection{Kindergarten $v S T M$}

The Woorden en zinnen nazeggen [Repeating Words and Sentences] subtest from the ESM-toets ([Test for children with Specific Language Impairment], Verhoeven, 2004) was used to assess vSTM. The task consists of two parts. In the first part, the child is instructed to repeat an increasing number of CVC words which can range from two words at the beginning to a maximum of seven words at the end. Each correctly repeated group of words scores as one point. The words are presented by the instructor at normal articulation speed. In the second part, the child is instructed to repeat sentences of an increasing length, ranging from seven words at the beginning to 17 words at the end. Once again, the sentences are presented by the instructor. Each correctly repeated sentence counts as two points. If only one error is made during the repetition of the sentence, one point is assigned. Both tasks are terminated when the child makes four successive errors. The maximum score for this subtest was 36 (12 for words and 24 for sentences). The Cronbach's alpha reliability coefficient for the subtest, as listed in the manual, was .88 , which indicates good reliability.

\subsubsection{Kindergarten phonological awareness}

Phonological awareness (PA) was assessed with the Screeninginstrument Beginnende Geletterdheid ([Screening Instrument for Emerging Literacy], Vloedgraven, Keuning, \& Verhoeven, 2009; Vloedgraven \& Verhoeven, 2007); using three phonological tasks (phoneme identification, phoneme segmentation and phoneme deletion); and using a letter knowledge task. Each of the phonological tasks starts with the presentation of three response alternatives both visually and auditory, followed by the auditory presentation of the target word. For phoneme identification, the target word is pronounced along with the first phoneme of the target word. The child must select that picture which starts with the same phoneme as the target word. For phoneme segmentation, the individual phonemes of the target word are pronounced. The child must select that picture which corresponds to the target word. For phoneme deletion, the target word is pronounced along with a phoneme to be deleted. The child must select the picture of the word which remains after deletion of the pronounced phoneme. All of the phonological tasks consist of high-frequency monosyllabic words selected from the Dutch word frequency list (Schaerlaekens \& Kohnstamm, 1999). Each task is composed of 2 practice items and 10 test items. Finally, in the receptive letter knowledge task, four lower case letters are visually presented on a computer screen during each trial. One 
of the letters is pronounced. The task of the child is to select the correct letter. All of the letters in the Dutch alphabet are used, except for the four infrequently occurring letters of 'c', ' $x$ ', ' $q$ ' and ' $y$ '. These letters have been replaced by digraphs (e.g., 'aa', 'oo', etc.). The receptive letter knowledge task is composed of 5 practice items and 34 test items. Feedback is only given on the practice trials. The number of correct items for the four tasks were summed to produce a raw PA score, which fulfilled the assumption of normality.

\subsubsection{First grade lexical retrieval}

Naming speed was again assessed in first grade using the two RAN tasks (Van den Bos et al., 2002; Van den Bos \& Lutje Spelberg, 2007). In addition to the two cards with objects and colours used in kindergarten, cards with numbers and letters were also now used. For the numbers, the card consists of the numbers 2, 4, 5, 8 and 9 listed in five columns with ten items each for a total of 50 items. The card with letters consists of the lower case letters 'd', 'o', 'a', 's' and 'p'. The child must name the items on the cards as quickly and accurately as possible. The time to name the 50 items for each type of stimulus is measured and converted into standard scores. The scores on the four tasks were summed to produce a raw score and this fulfilled the assumption of normality.

\subsubsection{First grade $v S T M$}

Same task as in kindergarten (see Section 2.2.3).

\subsubsection{First grade phonological awareness}

PA was assessed in first grade using the same tasks as in kindergarten. However, the number of items used in each phonological task was increased with 5 difficult items in an attempt to prevent ceiling effects (Vloedgraven \& Verhoeven, 2007). The mean score for the first graders on the letter knowledge task was found to be at ceiling level, which shows this skill to have been mastered by the majority of these children. We therefore included only the scores for phoneme identification, phoneme segmentation and phoneme deletion in the PA measure. The composite PA score fulfilled the assumption of normality.

\subsubsection{First grade word reading}

The reading level of the first graders was assessed using a standardized Dutch reading test, the Drie-Minuten-Toets (DMT, [Three-Minutes-Test], Verhoeven, 1995). The DMT consists of three cards containing 150 words on cards 1 and 2 each and 120 words on card 3 . The words presented on the cards differ in their complexity. The children are instructed to read as many words as possible in $1 \mathrm{~min}$ out loud for each of the cards. The test score is the total number of correctly produced words. For the present study, only the first card (DMT1: CVs, VCs or CVCs) and the second card (DMT2: monosyllabic words containing consonant clusters) were used to assess the reading levels of the children. The third card contains words with multiple syllables and was thus considered too difficult for the first-grade children who were just starting to receive reading instruction. The Cronbach's alpha reliability coefficients for cards 1 and 2 when used for first grade, as listed in the manual, were .88 and .96 , respectively. The scores for the two cards were summed to produce a first grade word-reading score.

\subsubsection{First grade nonword reading}

The non-word reading ability of the first graders was assessed using the Klepel (Van den Bos et al., 1994). The Klepel is a standardized Dutch non-word reading test consisting of 116 non-words of increasing difficulty. The children are instructed to read the non-words as quickly as possible without making errors aloud. The score on this task is the number of non-words read correctly in $2 \mathrm{~min}$. The Cronbach's alpha reliability coefficient for the non-word task, as listed in the manual, was .93, suggesting excellent reliability.

\subsection{Categorical perception stimuli and tasks}

\subsubsection{Categorical perception stimuli}

An eight-step radial continuum ranging from /bə/ to /də/ (consonants /b/and/d/followed by the neutral vowel/o/; schwa) varying along the place-of-articulation was used (Fig. 1). This continuum was created with sinewave analogues of speech sounds and was based on CP studies in French (Serniclaes, 2010). The stimuli were generated using parallel formant synthesis and the software developed by Carré (2004). The endpoints were given appropriate values for the perception of /də/ at S1 and /bo/ at S8, and successive stimuli were one Bark apart. The difference in place-of-articulation between the stimuli was created by modifying the onset of the initial frequency of the second and third formants (F2 and F3; Fig. 2). The end frequencies of the F2 and F3 transitions were fixed at $1500 \mathrm{~Hz}$ and $2500 \mathrm{~Hz}$, respectively. The initial frequency of the first formant (F1) was $300 \mathrm{~Hz}$, and its end frequency was $500 \mathrm{~Hz}$. The VOT was $-80 \mathrm{~ms}$, the duration of all frequency transitions was $40 \mathrm{~ms}$ and the duration of the stable vocalic segment was $80 \mathrm{~ms}$, which results in a total duration of $200 \mathrm{~ms}$ for each stimulus. In the context of the neutral vowel (schwa), the place boundaries of the continuum used in the present study tend to correspond to the flat transitions of the F2 (between S2 and S3) and F3 (between S6 and S7) and are related to natural psychoacoustic discontinuities (Serniclaes \& Geng, 2009). These psychoacoustic discontinuities are phonologically irrelevant in Dutch, a language with only two place-of-articulation categories for voiced stops (/b/and /d/), but phonologically relevant for a language like Hungarian, a language with four place categories (Serniclaes \& Geng, 2009). Furthermore, the advantage of 


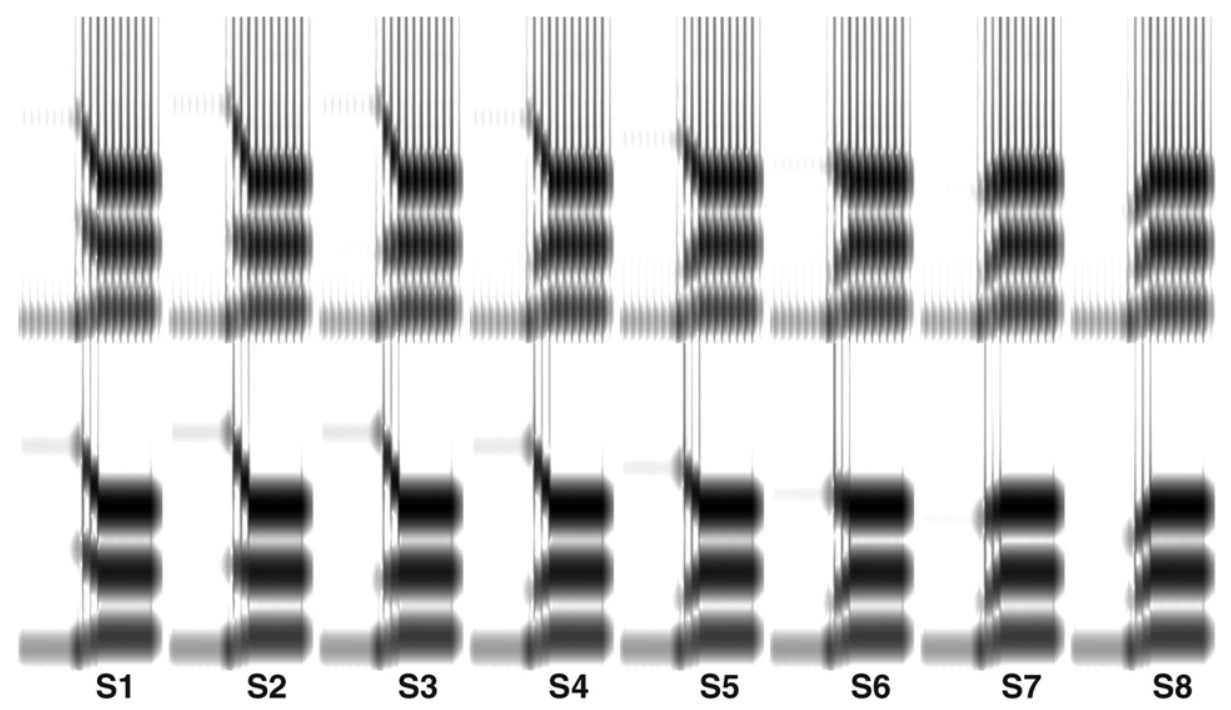

Fig. 1. Spectrograms for the synthetic speech stimuli (upper panels) and non-speech stimuli (lower panels). For the eight speech stimuli: S1 represents /da/ and $\mathrm{S} 8$ represents /bə/.

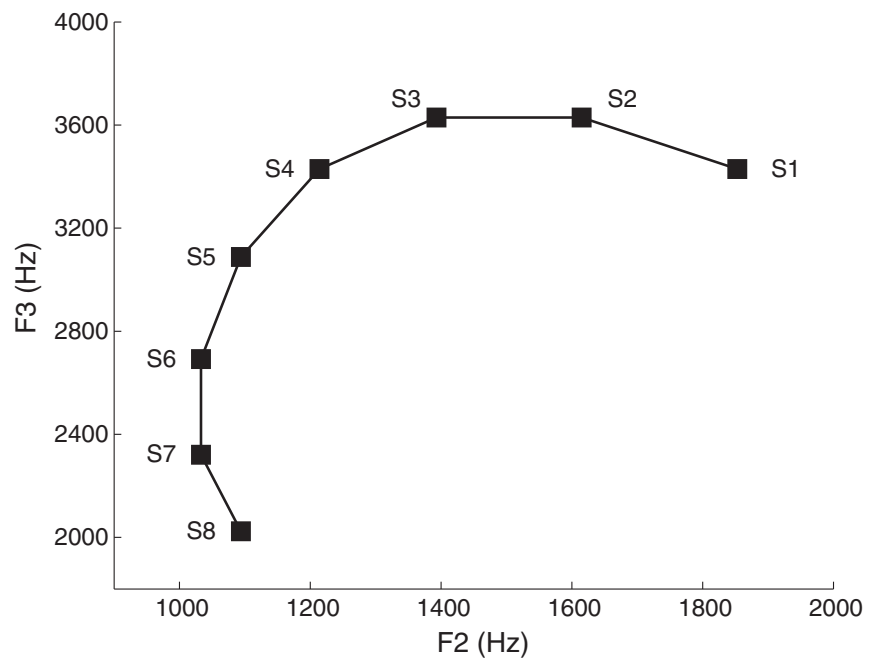

Fig. 2. Onset frequencies for the F2 and F3 from the /bə/-/də/ place-of-articulation continuum.

a place-of-articulation continuum with well-specified allophonic boundaries for evidencing sensitivity to allophonic contrasts, is that the location of these contrasts on the continuum are known in advance.

Two different versions of this continuum were constructed. The versions differed only with respect to synthesis method. There was a non-speech continuum (pure sinewave synthesis) and a speech continuum (pitch-modulated sinewave synthesis). The non-speech stimuli are similar to those known as sinewave speech (Remez, Rubin, Berns, Pardo, \& Lang, 1994). For the speech continuum, a low frequency amplitude modulation was added to the sinewave sounds (as in Serniclaes et al., 2001). These speech stimuli are similar to traditionally Klatt-synthesized stimuli.

\subsubsection{Categorical discrimination task}

In the discrimination task, an AXB paradigm was used. In an AXB design, there is no need for the participants to label the stimuli or remember associations between stimuli and response buttons. Participants only need to compare the adjacent stimuli, and it is possible to make a correct response on the basis of hearing just the first two stimuli (which will be either same or different). The third stimulus simply provides confirmatory evidence. Such a paradigm is suitable for children who tend to have difficulties on short-term memory tasks.

During the task, three dinosaurs were shown on the screen (cf. Bishop, Adams, Nation, \& Rosen, 2005). Two dinosaurs were located in the left and right corners at the bottom of the screen (the 'baby dinosaurs'), and one was located in the middle above the other two (the 'mother dinosaur'). On each trial three sounds were presented, separated by $400 \mathrm{~ms}$. The corresponding dinosaur jumped when the sound was presented. The task for the child was to indicate which of the two baby 
dinosaurs made the same sound as the mother dinosaur by pressing the appropriate button on a response box. When the child pressed the button, the corresponding baby dinosaur jumped again to confirm the choice. The next trial started $1500 \mathrm{~ms}$ after the response.

The experiment was self-paced. The task started with a demonstration screen to introduce the child to the task. This was followed by eight practice trials in which only the endpoints of the continuum were randomly presented. To continue the experiment, the child had to perform correctly on at least 6 out of 8 practice trials in a maximum of four practice rounds. Feedback was provided only during the practice trials. The experimental materials were divided into three blocks, and each block was separated by a short break. Stimulus pairs consisted of two step differences (e.g., S1-S3-S3; S2-S2-S4), with a total of 24 AXB pairs per block. A pilot study with 14 typically developing kindergarten children showed stimulus pairs with one-step differences to be too difficult as the children performed at chance in this condition. Stimulus pairs were presented in a pseudorandom order with the constraint that no more than three identical answers could be expected in consecutive trials.

\subsubsection{Categorical identification task}

The identification responses were collected in a two alternatives forced choice task (2AFC). In this task, two dinosaurs (the 'babies') were located in the middle of the screen in the vertical dimension. In the horizontal dimension, one dinosaur was located on the left side of the screen and another on the right side. On each trial, a sound was presented and the child had to press the button of the correct dinosaur on a response box. The corresponding dinosaur jumped after a button press. The task started with a demonstration screen to introduce the child to the task, followed by a training sequence. During the training, each of the two baby dinosaurs was linked to one of the endpoints of the continuum. Each dinosaur was presented on the screen while the corresponding endpoint was played five times. In this way, the children were familiarized with the endpoints of the continuum and the corresponding dinosaur. After training, the task started with eight practice trials in which only the endpoints of the continuum were randomly presented. To continue the experiment, the child had to perform correctly on at least 6 out of 8 practice trials in a maximum of four practice rounds. Feedback was provided only during the practice trials. The eight stimuli constituting the continuum were presented five times in pseudo-random order, with the constraint that the same stimulus was not presented twice in a row and no more than three identical answers could be expected in consecutive trials.

\subsection{Procedure}

All of the children were tested individually in a quiet room at their schools. The phonological awareness and categorical perception tasks were presented on a laptop (Dell Latitude D830). During the categorical perception tasks, the stimuli were presented binaurally through Sennheiser HD 555 headphones at a comfortable hearing level of approximately 65 dB. The presentation and response registration was controlled by E-Prime 1.2 (Schneider, Eschmann, \& Zuccolotto, 2002). In kindergarten, the speech condition was preceded by the non-speech condition because previous studies showed that if naïve listeners are not instructed for listening to sinewave speech, they perceive the sounds as whistles instead of speech (Dehaene-Lambertz et al., 2005; Dufor et al., 2009; Remez, Rubin, Pisoni, \& Carrell, 1981; Serniclaes et al., 2001). They therefore listened to the sinewave stimuli in the non-speech mode. It is important to note, however, that for this reason, the non-speech task was only administered in kindergarten. The duration of the categorical perception tasks was approximately $30 \mathrm{~min}$ : $20 \mathrm{~min}$ for the discrimination task and $10 \mathrm{~min}$ for the identification task in both the non-speech and speech conditions. In kindergarten, the non-speech and speech conditions were separated by a few hours because of the relative short attention spans of children. Procedures were approved by the Central Committee on Research Involving Human Subjects (CCMO), the Hague, the Netherlands.

\subsection{Data analyses}

\subsubsection{Discrimination scores}

For each subject and each stimulus pair (e.g., S1S3), we calculated the mean percentage correct for the four possible stimulus combinations (e.g., S1S1S3, S1S3S3, S3S1S1 and S3S3S1). Differences in CP were determined by comparing the observed discrimination scores with those which could be expected on the basis of the children's identification scores, which were calculated using the elementary probability formulas of Pollack and Pisoni (1971). The percentage correct discrimination scores were arcsine transformed prior to statistical analysis.

\subsubsection{Identification scores}

For each subject, we calculated the percentage correct /bə/ responses for each stimulus and the percentage correct sinewave /bo/ responses for the non-speech stimuli. The slope of the identification data was assessed for each subject separately using logistic regression with the identification response as the dependent variable and stimulus as the independent variable.

$y=\operatorname{logit}(p)=\log \left[\frac{p}{1-p}\right]=I+S \times$ stimulus 
where $I$ stands for the intercept and $S$ for the slope of the identification function. The stimulus boundary is located at $p=.5$ or to $\operatorname{logit}(p)=0$ and is obtained as follows:

$I+S \times$ Stimulus $_{\text {boundary }}=0$,

Stimulus boundary $=\frac{-I}{S}$.

The slope is an index of identification consistency: the steeper the slope, the higher the degree of consistency in the labelling of the continuum.

\subsubsection{Statistical tests}

Identification and discrimination data were analysed in analyses of variance (ANOVAs). The identification data was evaluated in two repeated measures ANOVAs with Group as the between-subjects variable and Time (kindergarten vs. first grade) as the within-subjects variable with either the slope or the boundary of the identification function as the dependent variable. For the discrimination data, first the differences in CP (i.e., the relation between the observed and expected discrimination scores) were analysed in a repeated measures ANOVA with Group as the between-subjects variable and Task (observed vs. expected), Time (kindergarten vs. first grade) and stimulus Pair (S1S3, S2S4, S3S5, S4S6, S5S7 and S6S8) as the within-subjects variables. When a significant interaction involving Time and/or Group was found, separate ANOVAs were performed. Greenhouse-Geisser corrections for violation of the sphericity assumption were applied when appropriate; the original degrees of freedom and $p$-values after the correction are reported (Greenhouse \& Geisser, 1959).

\section{Results}

\subsection{Descriptive data}

Table 1 displays the means and group differences for nonverbal intelligence, vSTM, RAN, phonological measures and reading skills in kindergarten and first grade. From kindergarten to first grade, one of the at-risk children and one of the control children repeated kindergarten and were therefore excluded from the study. Another control child withdrew from the study in first grade. In the end, the at-risk group consisted of 32 children between 76 and 92 months of age (17 girls and 15 boys, $M_{\text {age }}=83.1$ months); the control group consisted of 38 children between 72 and 93 months of age (20 girls and 18 boys, $M_{\text {age }}=83.6$ months).

\subsection{Auditory processing of speech vs. non-speech}

The non-speech tasks were only administered in kindergarten because repeated exposure to sinewave stimuli can make participants perceive them as speech like. However, only about half of the at-risk children and slightly more than half of the control children passed the practice criterion in this condition. Furthermore, both the at-risk and control children scored at or near chance level on both the non-speech identification and discrimination tasks. Given that the non-speech tasks were found to be too difficult for the children in kindergarten, this data was not analysed further (cf. Davids et al., 2011).

\subsection{Speech identification in kindergarten versus first grade}

Out of the 73 children initially included in the study, 56 completed the identification task in both kindergarten and first grade ( 24 at-risk and 32 controls). The top left and right panels of Fig. 3 show the identification performance of the control versus at-risk children in kindergarten (left) and first grade (right). Comparison of the figures shows steeper identification functions for both the at-risk and control children in first grade compared to kindergarten but otherwise very few differences between the groups. To analyse the differences in the mean slopes and boundaries for the kindergarten versus first grade children and the at-risk versus control children, two repeated measures ANOVAs with Time (kindergarten vs. first grade) as the within-subjects variable and Group (at-risk vs. control) as the betweensubjects variable were performed. For the slope, these revealed a significant main effect of Time $(F(1,54)=4.44, p=.04$, $\eta_{p}^{2}=.08$ ), a nonsignificant Time $\times$ Group interaction and no Group effect (both $F s<1$ ). We thus found a general increase in the slope between kindergarten $\left(M_{\text {slope }}=.012\right.$ logit; $\left.S D=.02\right)$ and first grade $\left(M_{\text {slope }}=.076 \operatorname{logit} ; S D=.24\right)$ but no significant differences in the slope between the groups of children during each time period. For the boundary data, no significant effects were found: the effects of both Time and Group were nonsignificant (both Fs $<1$ ) and the Time $\times$ Group interaction was also nonsignifcant $\left(F(1,49)=1.22, p=.28, \eta_{p}^{2}=.02\right)$. This result shows the boundary to be located at the same point along the continuum in both kindergarten and first grade, namely between stimuli S3 and S4, which is just one step before the midpoint.

\subsection{Speech discrimination in kindergarten versus first grade}

Out of the 73 children initially included in the study, 59 completed the discrimination task in both kindergarten and first grade (26 at-risk and 33 controls). The lower left and right panels of Fig. 3 show the discrimination performance of the 

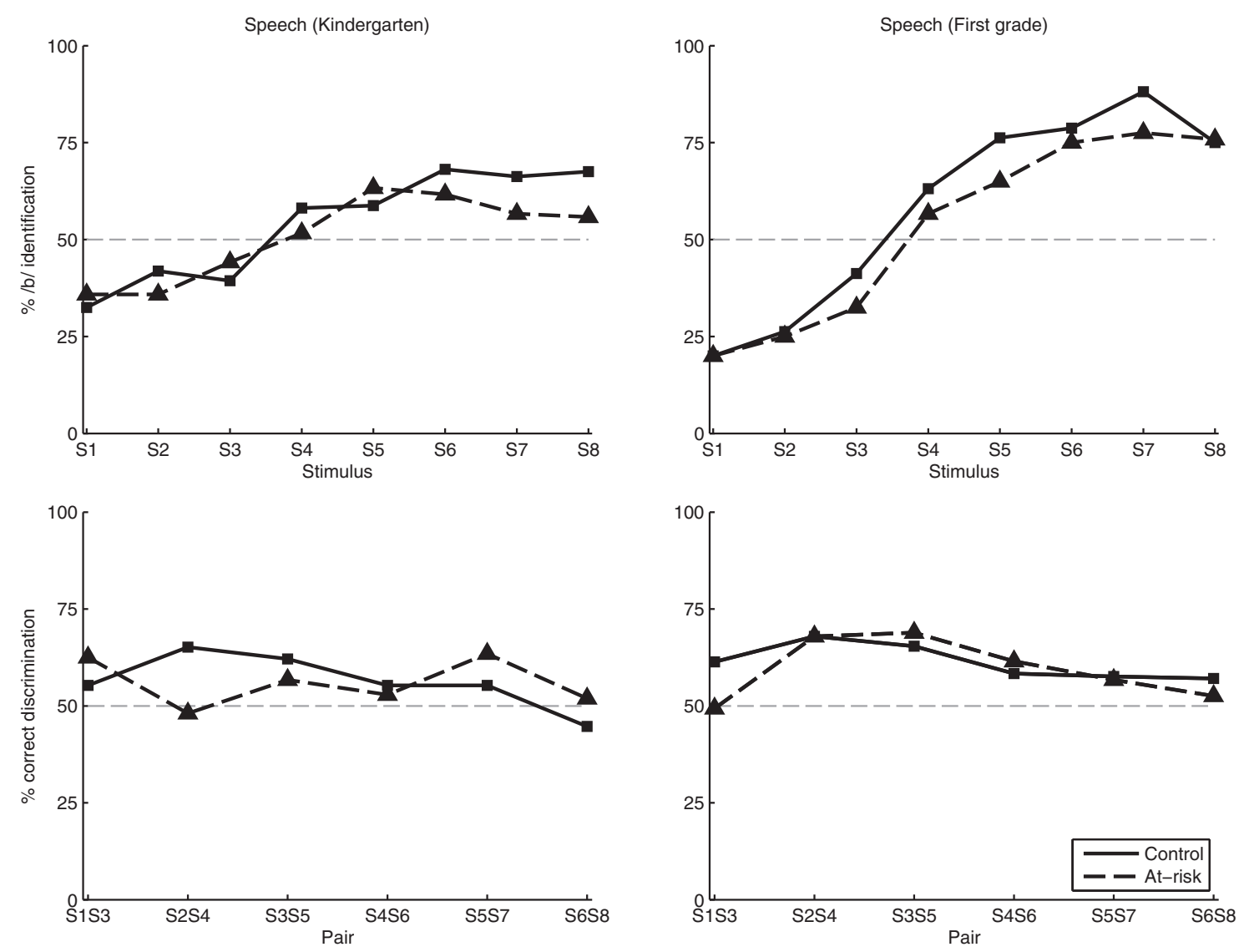

Fig. 3. Mean identification functions (top panels) and discrimination functions (lower panels) for at-risk and control children on speech stimuli in kindergarten versus first grade (left and right panels, respectively).

control versus at-risk children in kindergarten (left) and first grade (right). Comparison of the figures shows a discrimination peak for the between category pairs (S2S4 and S3S5) for the control children in kindergarten but peaks for both the stimuli pairs S1S3 and S5S7 for the at-risk children in kindergarten. However, in first grade, both the control and at-risk children show discrimination peaks at the between category pairs. Differences in CP were tested in a repeated measures ANOVA with Group (at-risk vs. control) as the between-subjects variable and Task (observed vs. expected discrimination scores), Time (kindergarten vs. first grade) and Pair (S1S3, S2S4, S3S5, S4S6, S5S7 and S6S8) as the within-subjects variables. We found a significant main effect of Pair $\left(F(5,250)=13.15, p<.001, \eta_{p}^{2}=.21\right)$, Time $\times$ Pair interaction $(F(5,250)=3.13, p=.01$, $\left.\eta_{p}^{2}=.06\right)$, Time $\times$ Pair $\times$ Group interaction $\left(F(5,250)=2.76, \quad p=.02, \quad \eta_{p}^{2}=.05\right)$ and a marginally significant Task $\times$ Time $\times$ Pair $\times$ Group interaction $\left(F(5,250)=2.09, p=.067, \eta_{p}^{2}=.04\right)$ but no effect of Group $(F<1)$. Given a significant Time $\times$ Pair $\times$ Group interaction, individual Pair $\times$ Group ANOVAs were conducted for kindergarten and first grade separately with the observed and expected discrimination pairs taken together.

For kindergarten (lower left panel in Fig. 3), a repeated measures ANOVA with Group (at-risk vs. control) as the betweensubjects variable and Pair (S1S3, S2S4, S3S5, S4S6, S5S7 and S6S8) as the within-subjects variable showed a significant Pair $\times$ Group interaction $\left(F(5,255)=2.30, p=.046, \eta_{p}^{2}=.04\right)$, a significant main effect of Pair $(F(5,255)=3.33, p=.01$, $\left.\eta_{p}^{2}=.06\right)$ and no main effect of Group $(F<1)$. Planned contrasts for the significant Pair $\times$ Group interaction indicated a significant difference in the discrimination of the phonemic contrast (i.e., between stimulus pairs S2S4 and S3S5, which straddle the phoneme boundary, and the four other pairs) by the at-risk versus control groups $(F(1,59)=5.69, p=.02$, $\eta_{p}^{2}=.10$ ), with the control group showing higher scores on the pairs crossing the phonemic boundary.

For the first-grade children (lower right panel in Fig. 3), a repeated measures ANOVA with Group (at-risk vs. control) as the between-subjects variable and Pair (S1S3, S2S4, S3S5, S4S6, S5S7 and S6S8) as the within-subjects variable indicated a significant main effect of Pair $\left(F(5,280)=20.37, p<.001, \eta_{p}^{2}=.27\right)$, no significant Pair $\times$ Group interaction and no significant effect of Group $\left(F(5,280)=1.70, p=.14, \eta_{p}^{2}=.03 ; F<1\right.$, respectively). Planned contrasts for the significant effect of Pair indicated a significant difference in the discrimination of the phonemic contrast by the children in first grade $\left(F(1,56)=69.09, p<.001, \eta_{p}^{2}=.55\right)$.

To gain greater insight into the allophonic perception of particularly the children at risk for dyslexia, the at-risk group was separated into subgroups on the basis of their first grade PA scores. This produced a low PA subgroup of 9 children at-risk for 

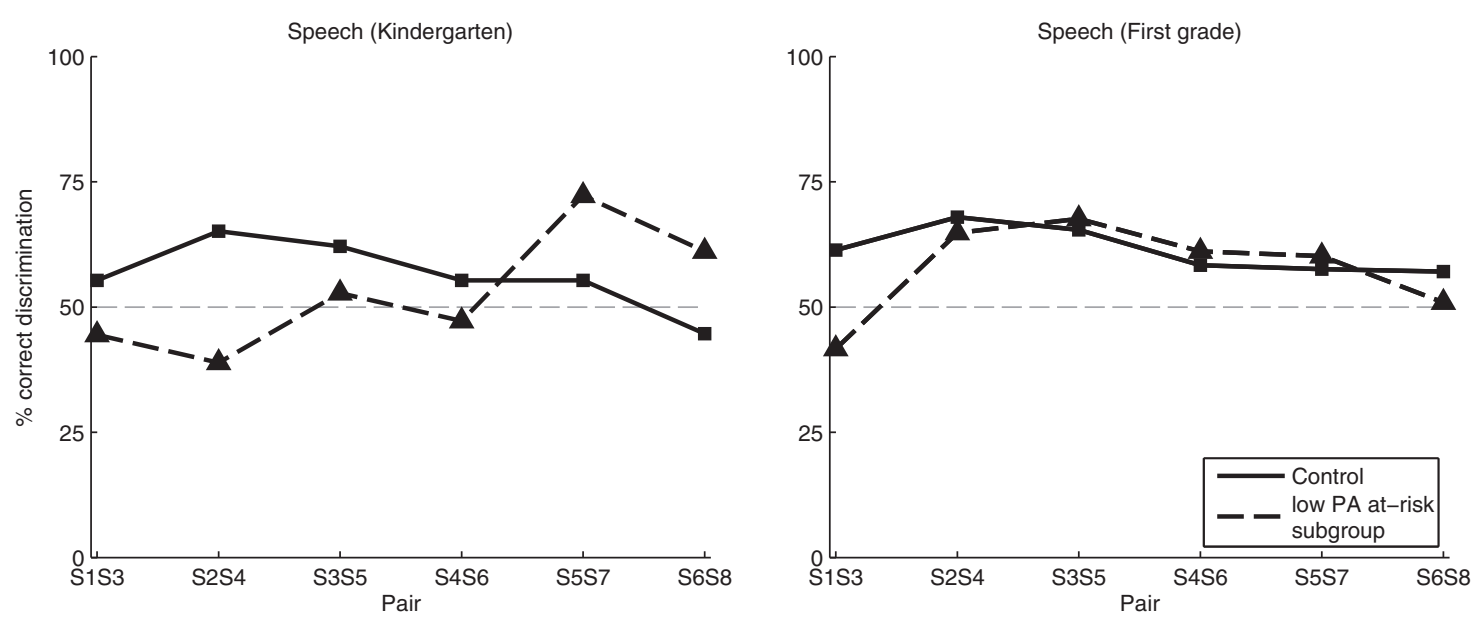

Fig. 4. Mean discrimination functions for speech stimuli in kindergarten and first grade (left and right panels, respectively) by children who are at risk for dyslexia and scored one standard deviation or more below the group mean for the control children on phonological awareness and control children.

dyslexia and scoring one standard deviation or more below the group mean for the control group. For kindergarten, a repeated measures ANOVA with Group (low PA at-risk subgroup vs. control) as the between-subjects variable and Pair (S1S3, S2S4, S3S5, S4S6, S5S7 and S6S8) as the within-subjects variable indicated a significant Pair $\times$ Group interaction $(F(5$, $175)=2.70, p=.02, \eta_{p}^{2}=.07$ ). Planned contrasts for the significant Pair $\times$ Group interaction showed a significant difference in the discrimination of the phonemic contrast (between stimulus pairs S2S4 and S3S5, which straddle the phoneme boundary, and the four other pairs) for the low PA at-risk subgroup versus control group $\left(F(1,35)=5.23, p=.03, \eta_{p}^{2}=.13\right)$, with the control group showing higher scores on this contrast (Fig. 4). In addition, planned contrasts for the discrimination of the F3 allophonic contrast (between the stimulus pairs S5S7 and S6S8, which straddles the F3 allophonic boundary, and the stimulus pair S4S6, which straddles neither a phonemic nor an allophonic boundary) revealed a significant difference between the groups $\left(F(1,35)=4.50, p=.04, \eta_{p}^{2}=.11\right)$, with the low PA subgroup of at-risk children showing a higher score on this contrast.

For the first grade children, a repeated measures ANOVA with Group (low PA at-risk subgroup vs. control) as the betweensubjects variable and Pair (S1S3, S2S4, S3S5, S4S6, S5S7 and S6S8) as the within-subjects variable indicated a significant main effect of Pair $\left(F(5,200)=8.73, p<.001, \eta_{p}^{2}=.18\right)$ and no significant Pair $\times$ Group interaction $(F(5,200)=1.39, p=.25$, $\left.\eta_{p}^{2}=.03\right)$ or main effect of Group $\left(F(1,40)=1.51, p=.23, \eta_{p}^{2}=.04\right)$. Planned contrasts for the significant main effect of Pair showed a significant difference in the discrimination of the phonemic contrast by children in first grade $(F(1,40)=28.88$, $p<.001, \eta_{p}^{2}=.42$; Fig. 4 ).

The results can be summarized as follows. In kindergarten, the identification performance for the speech stimuli was similar for the at-risk and control children with the boundary placed one step before the midpoint of the continuum. Differences between the at-risk and control children were found for the discrimination of speech stimuli, with the kindergarten control children better discriminating stimuli crossing the phoneme boundary and the kindergarten at-risk children with low phonological awareness better discriminating pairs within the same category. There were no differences in the $\mathrm{CP}$ of the control versus at-risk children, as evidenced by nonsignificant interactions involving Task (observed vs. expected discrimination scores). In first grade, the identification of the speech stimuli was similar for the control versus atrisk children, although the first-grade slopes were significantly steeper than the kindergarten slopes. Furthermore, the absence of significant Pair $\times$ Group interactions in the discrimination task indicated a similar discrimination strategy for both the control versus at-risk children and the control versus at-risk children with low phonological awareness in first grade.

\section{Discussion}

In the present study, we investigated the categorical perception of /bə-də/ syllables along a place-of-articulation continuum in Dutch children at risk for dyslexia and chronological age-matched controls in kindergarten and first grade. We examined whether children at risk for dyslexia show an auditory deficit in kindergarten and attempted to disentangle its nature and persistence after the start of formal reading instruction in first grade. We found, to start with, that the at-risk children in kindergarten performed significantly lower on tasks tapping into phonological awareness and the retrieval of phonological codes from long term memory (e.g., RAN) than the control children in kindergarten, which suggests a phonological deficit in the at-risk children. In first grade, the at-risk children performed significantly lower on not only the tasks tapping into phonological awareness but also on the standardized word and non-word reading tasks. The results of the speech perception tasks showed an allophonic mode of speech perception in the kindergarten children at risk for dyslexia as 
evidenced by better discrimination of the within-category pair S5S7, which straddles the psychoacoustic discontinuities associated with changes in the upward/downward direction of the F3 transition, while the control children displayed a phonemic mode of speech perception as evidenced by better discrimination of the stimulus pairs straddling the phoneme boundary. However, the performance of the same children later in first grade showed those at risk for dyslexia to have shifted from an allophonic mode of speech perception towards a phonemic mode of speech perception.

It should be noted that the non-speech perception tasks proved too difficult for the kindergarten children in general, with both the control and at-risk children performing near chance on both the identification and discrimination tasks with nonspeech stimuli. The high exclusion rates based on the threshold in the practice trials for the non-speech tasks also indicated this.

How do these results relate to our three questions? Our first question was whether the perceptual deficit often associated with developmental dyslexia is specific to speech or of a more general nature. Some researchers claim that dyslexia may be related to a general auditory deficit (e.g., Tallal, 1980; Vandermosten et al., 2010) while others claim that the auditory processing deficits in individuals with dyslexia are specific to speech (e.g., Mody et al., 1997; White et al., 2006). In the present study, the performance on the non-speech tasks was only slightly above chance for both the control and at-risk children, which means that the evidence was too minimal to allow any firm conclusions to be drawn with regard to the speech-specific or general nature of the auditory problems in the children we studied.

Our second research question was whether children at risk for developmental dyslexia show an allophonic mode of speech perception. First, we will discuss the speech identification results; then we will discuss the speech discrimination results. For the speech stimuli, we found the slope and location of the boundary of the identification functions to be comparable for the at-risk versus control children in kindergarten and first grade. This finding is in line with the findings of a study showing 5-year-old children at risk for dyslexia to not differ from control children on the identification of a speech continuum ranging from / bAk/ to /dAk/ with only marginal differences in discrimination (Boets, Ghesquière, Van Wieringen, \& Wouters, 2007). In contrast, a study comparing younger children at risk for dyslexia with 3-to 4-year-old control children showed better identification of speech sounds $(/ \mathrm{p} /-/ \mathrm{k} /$ ) by the control group (Gerrits \& De Bree, 2009). Still other studies of school-aged children diagnosed with dyslexia versus control children have reported mixed results when comparing the slopes of the identification functions, shallower slopes are sometimes found for the children with dyslexia (e.g., Joanisse et al., 2000; Maassen et al., 2001; Manis et al., 1997) while others report comparable slopes for individuals with dyslexia and controls (e.g., Blomert \& Mitterer, 2004; Bogliotti et al., 2008; Liu, Shu, \& Yang, 2009). While Bogliotti et al. (2008) found differences in the floor and ceiling effects (i.e., identification responses outside the boundary region) for individuals with dyslexia versus controls, differences in the floor and ceiling effects were not found for the children at risk for dyslexia versus control children in the present study. The fact that we studied an at-risk group rather than a well-defined clinical group may account for the comparable identification functions in the present study. Studying children at risk for dyslexia versus children actually diagnosed with dyslexia may also explain the mixed results for the identification of speech sounds found in other studies. Differences in the slope of the identification function between dyslexic children and control children may only be a matter of delay because there is ample evidence that the slope of the identification function (i.e., boundary precision) increases with age (e.g., Burnham, 2003; Hazan \& Barrett, 2000; Medina et al., 2010). In the present study, we found a significant increase in the slope of the identification function for the children in general from kindergarten to first grade (see Fig. 3); this shows phonemic categorization to be developing in these children. Finally, the location of the boundary was similar in kindergarten and first grade, which is consistent with the results of Medina et al. (2010), and did not differ for the at-risk versus control children.

The results on the speech discrimination task showed kindergarten children at risk for dyslexia with also particularly low phonological awareness to discriminate stimuli which cross psychoacoustic discontinuities (i.e., the change in upward/ downward directions of F2 or F3 transitions) and not stimuli which cross phonemic boundaries while children not at risk for dyslexia (i.e., the control children) only discriminated stimuli which cross a phonemic boundary. The answer to our second research question is thus positive: children at risk for dyslexia show signs of an allophonic mode of speech perception.

Contrary to our expectations, the sensitivity of the at-risk children to psychoacoustic discontinuities did not affect the degree of categorical perception; the present results did not reveal significant differences in the observed versus expected discrimination scores for the at-risk versus control children. The important point, however, is the marked sensitivity of the at-risk children to changes in the upward/downward direction of F2 or F3 transitions. This is a hallmark of allophonic speech perception because these psychoacoustic discontinuities are phonologically irrelevant in Dutch, a language with only two place-of-articulation categories for voiced stops (/b/and /d/), but phonologically relevant for a language like Hungarian, a language with four place categories (Serniclaes \& Geng, 2009). While our findings are in line with those of previous studies showing an allophonic mode of speech perception in older children diagnosed with dyslexia (e.g., Bogliotti et al., 2008; Serniclaes et al., 2004), our study is the first to show an allophonic mode of speech perception in children at risk for dyslexia and also well before the start of formal reading instruction. The fact that the allophonic versus phonemic modes of speech perception were already present before the start of formal reading instruction, moreover, suggests that the allophonic mode of speech perception may be a cause and not an effect of later reading problems.

This brings us to our third research question, which was whether the onset of formal reading instruction influences the mode of speech perception or not. Our expectation, based on evidence for an allophonic mode of speech perception in both children and adults diagnosed with dyslexia, was that it would not. In contrast to what we expected, we found that the children at risk for dyslexia in kindergarten had shifted from an allophonic mode of speech perception to a more phonemic 
mode of speech perception in first grade, when formal reading instruction begins. This loss of allophonic speech perception can be explained by the findings of Burnham (2003) and Burnham, Earnshaw, and Clark (1991), who have shown children around the onset of reading to have a heightened perception of language-specific speech contrasts. In these studies, phonologically relevant contrasts for English and phonologically irrelevant contrasts (e.g., Thai and Hindi) were presented to subjects of different ages and with different amounts of school experience. It was found around the onset of reading that the perception of language-specific speech contrasts (i.e., native contrasts) was maximal and the perception of both non-native and non-speech contrasts was minimal. The authors suggested that around the onset of reading, children may adopt a strategy in which the perception of all contrasts which are not phonologically relevant is suppressed. In addition, they suggest that children who are taught to read using a phonics-based method (i.e., grapheme-phoneme conversion rules), as is the case in the Netherlands, will have greater language-specific speech perception than children who are taught using a whole-word method. This explains how the allophonic mode of speech perception may be found in studies of older children and adults diagnosed with dyslexia (e.g., Bogliotti et al., 2008; Dufor et al., 2009; Serniclaes et al., 2001). After first grade, the heavy emphasis on decoding decreases and the suppression of non-native speech contrasts in particularly children with dyslexia may also therefore dissipate. Obviously, this account is somewhat speculative, but more data collected in a similar manner for different ages should shed greater light on things and help us determine if the allophonic mode of speech perception in at-risk and dyslexic children is only briefly absent at the onset of reading or absent more permanently.

To conclude, the present study is the first to find evidence for an allophonic mode of speech perception in children at risk for dyslexia in kindergarten. We also found these same children to shift from an allophonic mode of speech perception to a phonemic mode of perception, probably under the influence of a phonics-based instructional reading programme, in first grade. It was speculated that the shift to a phonemic mode of speech perception is only temporary and that the allophonic mode of speech perception returns in at least a subgroup of children who are at risk for dyslexia. For these children, the use of an allophonic mode of speech perception affects the process of mapping graphemes onto phonemes and can thus be seen as a clinical marker of actual reading problems. Understanding written language requires well-defined phonological representations. The use of more phonological representations than are necessary to perceive phonemes in the ambient language is known to result in a mismatch between grapheme and phoneme categories with major implications for the development of reading skills, even in a transparent language. Although transparent languages have a one-to-one relationship between graphemes and phonemes (e.g., Italian), there are still several allophones for each phoneme which results in a many-to-one relationship when using an allophonic perception. The impact of an allophonic perception on an opaque language such as English, is much greater as many-to-one relationships are necessary for reading acquisition in these languages. Despite the growing body of evidence regarding the causes of dyslexia, children at risk for dyslexia are still not diagnosed until they show problems with learning to read. By that time, however, the reading skills of these children lag considerably behind those of their classmates. We must therefore find out more about the precursors to dyslexia and the markers of such in order to prevent or at least diminish later reading deficits. And the present study has presumably contributed to this enterprise.

\section{References}

Adlard, A., \& Hazan, V. (1998). Speech perception in children with specific reading difficulties (dyslexia). Quarterly Journal of Experimental Psychology. A Human Experimental Psychology, 51(1), 153-177. doi:10.1080/027249898391800.

Aslin, R. N., Pisoni, D. B., Hennessy, B. L., \& Perey, A. J. (1981). Discrimination of voice onset time by human infants: New findings and implications for the effects of early experience. Child Development, 52(4), 1135-1145. doi:10.2307/1129499.

Bishop, D. V. M., Adams, C. V., Nation, K., \& Rosen, S. (2005). Perception of transient nonspeech stimuli is normal in specific language impairment: Evidence from glide discrimination. Applied Psycholinguistics, 26(02), 175-194. doi:10.1017/S0142716405050137.

Blomert, L., \& Mitterer, H. (2004). The fragile nature of the speech-perception deficit in dyslexia: Natural vs synthetic speech. Brain and Language, 89(1), 21-26. doi:10.1016/S0093-934X(03)00305-5.

Boets, B., Ghesquière, P., Van Wieringen, A., \& Wouters, J. (2007). Speech perception in preschoolers at family risk for dyslexia: Relations with low-level auditory processing and phonological ability. Brain and Language, 101(1), 19-30. doi:10.1016/j.bandl.2006.06.009.

Bogliotti, C., Serniclaes, W., Messaoud-Galusi, S., \& Sprenger-Charolles, L. (2008). Discrimination of speech sounds by children with dyslexia: Comparisons with chronological age and reading level controls. Journal of Experimental Child Psychology, 101(2), 137-155. doi:10.1016/j.jecp.2008.03.006.

Brus, B. T., \& Voeten, M. J. M. (1999). Eén-Minuut-Test [one-minute-test]. Lisse, The Netherlands: Swets \& Zeitlinger.

Burnham, D. (2003). Language specific speech perception and the onset of reading. Reading and Writing, 16(6), 573-609. doi:10.1023/a:1025593911070.

Burnham, D., Earnshaw, L. J., \& Clark, J. E. (1991). Development of categorical identification of native and non-native bilabial stops: Infants, children and adults. Journal of Child Language, 18(02), 231-260. doi:10.1017/S0305000900011041.

Carré, R. (2004). Program SyntFormVoy. [Computer software]. Lyon, France: Laboratoire Dynamique du Language, CNRS. Retrieved from http://pagespersoorange.fr/ren.carre/index.htm.

Castles, A., \& Coltheart, M. (2004). Is there a causal link from phonological awareness to success in learning to read? Cognition, 91(1), 77-111. doi:10.1016/S00100277(03)00164-1.

Chiappe, P., Chiappe, D. L., \& Siegel, L. S. (2001). Speech perception, lexicality, and reading skill.Journal of Experimental Child Psychology, 80(1), 58-74. doi:10.1006/ jecp. 2000.2624

Davids, N., Segers, E., Van den Brink, D., Mitterer, H., Van Balkom, H., Hagoort, P., et al. (2011). The nature of auditory discrimination problems in children with specific language impairment: An MMN study. Neuropsychologia, 49(1), 19-28. doi:10.1016/j.neuropsychologia.2010.11.001.

Dehaene-Lambertz, G., Pallier, C., Serniclaes, W., Sprenger-Charolles, L., Jobert, A., \& Dehaene, S. (2005). Neural correlates of switching from auditory to speech perception. Neuroimage, 24(1), 21-33. doi:10.1016/j.neuroimage.2004.09.039.

Démonet, J. F., Taylor, M. J., \& Chaix, Y. (2004). Developmental dyslexia. Lancet, 363(9419), 1451-1460. doi:10.1016/S0140-6736(04)16106-0.

Dufor, O., Serniclaes, W., Sprenger-Charolles, L., \& Démonet, J. F. (2009). Left premotor cortex and allophonic speech perception in dyslexia: A PET study. Neuroimage, 46(1), 241-248. doi:10.1016/j.neuroimage.2009.01.035.

Elbro, C., Nielsen, I., \& Petersen, D. K. (1994). Dyslexia in adults-Evidence for deficits in non-word reading and in the phonological representation of lexical items. Annals of Dyslexia, 44, 205-226. 
Gerrits, E., \& De Bree, E. (2009). Early language development of children at familial risk of dyslexia: Speech perception and production. Journal of Communication Disorders, 42(3), 180-194. doi:10.1016/j.jcomdis.2008.10.004.

Godfrey, J. J., Syrdal-Lasky, K., Millay, K. K., \& Knox, C. M. (1981). Performance of dyslexic children on speech perception tests. Journal of Experimental Child Psychology, 32(3), 401-424. doi:10.1016/0022-0965(81)90105-3.

Greenhouse, S., \& Geisser, S. (1959). On methods in the analysis of profile data. Psychometrika, 24(2), 95-112. doi:10.1007/bf02289823.

Grigorenko, E. L. (2001). Developmental dyslexia: An update on genes, brains, and environments. Journal of Child Psychology and Psychiatry, 42(1), 91-125. doi:10.1111/1469-7610.00704.

Harnad, S. (1987). Categorical perception: The groundwork of cognition. Cambridge: Cambridge University Press.

Hazan, V., \& Barrett, S. (2000). The development of phonemic categorization in children aged 6-12. Journal of Phonetics, 28(4), 377-396. doi:10.1006/ jpho.2000.0121.

Hoonhorst, I., Colin, C., Markessis, E., Radeau, M., Deltenre, P., \& Serniclaes, W. (2009). French native speakers in the making: From language-general to languagespecific voicing boundaries. Journal of Experimental Child Psychology, 104(4), 353-366. doi:10.1016/j.jecp.2009.07.005.

Hoonhorst, I., Medina, V., Colin, C., Markessis, E., Radeau, M., Deltenre, P., et al. (2010). Categorical perception of voicing, colors and facial expressions: A developmental study. Speech Communication, 53, 417-430. doi:10.1016/j.specom.2010.11.005.

Joanisse, M. F., Manis, F. R., Keating, P., \& Seidenberg, M. S. (2000). Language deficits in dyslexic children: Speech perception, phonology, and morphology. Journal of Experimental Child Psychology, 77(1), 30-60. doi:10.1006/jecp.1999.2553.

Kuhl, P. K. (2004). Early language acquisition: Cracking the speech code. Nature Reviews Neuroscience, 5(11), 831-843. doi:10.1038/Nrn1533.

Kuijpers, C. T. L., Van der Leij, A., Been, P. H., Van Leeuwen, T. H., Ter Keurs, M., Schreuder, R., et al. (2003). Leesproblemen in het voortgezet onderwijs en de volwassenheid [Reading problems in secondary education and adulthood]. Pedagogische Studiën, 80(4), 272-287.

Lasky, R. E., Syrdal-Lasky, A., \& Klein, R. E. (1975). VOT discrimination by four to six and a half month old infants from Spanish environments. Journal of Experimental Child Psychology, 20(2), 215-225. doi:10.1016/0022-0965(75)90099-5.

Liberman, A. M., Cooper, F. S., Shankweiler, D. P., \& Studdert-Kennedy, M. (1967). Perception of the speech code. Psychological Review, 74(6), 431-461. doi:10.1037/ h0020279.

Liberman, A. M., Harris, K. S., Hoffman, H. S., \& Griffith, B. C. (1957). The discrimination of speech sounds within and across phoneme boundaries. Journal of Experimental Child Psychology, 54(5), 358-368. doi:10.1037/h0044417.

Lieberman, P., Meskill, R. H., Chatillon, M., \& Schupack, H. (1985). Phonetic speech perception deficits in dyslexia. Journal of Speech and Hearing Research, 28(4), $480-486$.

Lisker, L., \& Abramson, A. S. (1964). Cross-language study of voicing in initial stops: Acoustical measurements. Word, 20, 384-422.

Lisker, L., \& Abramson, A. S. (1970). The voicing dimension: Some experiments in comparative phonetics. In B. Hála, M. Romportl, \& P. Janota (Eds.), In Proceedings of the 6th international congress of phonetic sciences (pp. 563-567). Prague: Academia.

Liu, W., Shu, H., \& Yang, Y. (2009). Speech perception deficits by Chinese children with phonological dyslexia. Journal of Experimental Child Psychology, 103(3), 338354. doi:10.1016/j.jecp.2009.03.005.

Maassen, B., Groenen, P., Crul, T., Assman-Hulsmans, C., \& Gabreëls, F. (2001). Identification and discrimination of voicing and place-of-articulation in developmental dyslexia. Clinical Linguistics \& Phonetics, 15(4), 319-339. doi:10.1080/02699200010026102.

Manis, F. R., McBride-Chang, C., Seidenberg, M. S., Keating, P., Doi, L. M., Munson, B., et al. (1997). Are speech perception deficits associated with developmental dyslexia? Journal of Experimental Child Psychology, 66(2), 211-235. doi:10.1006/jecp.1997.2383.

McBride-Chang, C. (1995). Phonological processing, speech perception, and reading disability: An integrative review. Educational Psychologist, 30(3), $109-121$. doi:10.1207/s15326985ep3003_2.

McMurray, B., Aslin, R. N., Tanenhaus, M. K., Spivey, M. J., \& Subik, D. (2008). Gradient sensitivity to within-category variation in words and syllables. Journal of Experimental Psychology: Human Perception and Performance, 34(6), 1609-1631. doi:10.1037/a0011747.

Medina, V., Hoonhorst, I., Bogliotti, C., \& Serniclaes, W. (2010). Development of voicing perception in French: Comparing adults, adolescents, and children. Journal of Phonetics, 38, 493-503. doi:10.1016/j.wocn.2010.06.002.

Mitterer, H., \& Cutler, A. (2006). Speech perception. In K. Brown (Ed.), Encyclopedia of language \& linguistics (2nd ed., pp. 770-782). Oxford: Elsevier.

Mody, M., Studdert-Kennedy, M., \& Brady, S. (1997). Speech perception deficits in poor readers: Auditory processing or phonological coding? Journal of Experimental Child Psychology, 64(2), 199-231. doi:10.1006/jecp.1996.2343.

Pollack, I., \& Pisoni, D. (1971). On the comparison between identification and discrimination tests in speech perception. Psychonomic Science, 24(6), 299-300.

Ramus, F. (2003). Developmental dyslexia: Specific phonological deficit or general sensorimotor dysfunction? Current Opinion in Neurobiology, 13(2), 212-218. doi:10.1016/S0959-4388(03)00035-7.

Ramus, F. (2004). Neurobiology of dyslexia: A reinterpretation of the data. Trends in Neurosciences, 27(12), 720-726. doi:10.1016/j.tins.2004.10.004.

Ramus, F., Rosen, S., Dakin, S. C., Day, B. L., Castellote, J. M., White, S., et al. (2003). Theories of developmental dyslexia: Insights from a multiple case study of dyslexic adults. Brain, 126(Pt 4), 841-865. doi:10.1093/brain/awg076.

Ramus, F., \& Szenkovits, G. (2008). What phonological deficit? Quarterly Journal of Experimental Psychology, 61(1), 129-141. doi:10.1080/17470210701508822.

Raven, J. C. (1965). Guide to using the coloured progressive matrices. London: HK Lewis.

Remez, R. E., Rubin, P. E., Berns, S. M., Pardo, J. S., \& Lang, J. M. (1994). On the perceptual organization of speech. Psychological Review, 101(1), 129-156. doi:10.1037//0033-295X.101.1.129.

Remez, R. E., Rubin, P. E., Pisoni, D. B., \& Carrell, T. D. (1981). Speech perception without traditional speech cues. Science, 212(4497), 947-949.

Rosen, S. (2003). Auditory processing in dyslexia and specific language impairment: Is there a deficit? What is its nature? Does it explain anything?. Journal of Phonetics, 31(3/4), 509-527. doi:10.1016/S0095-4470(03)00046-9.

Schaerlaekens, A., \& Kohnstamm, D. (1999). Streeflijst woordenschat voor zesjarigen in Nederland en België. [Vocabulary achievement in six-year-olds in the Netherlands and Belgium]. Lisse, The Netherlands: Swets \& Zeitlinger.

Schneider, W., Eschmann, A., \& Zuccolotto, A. (2002). E-Prime user's guide. Pittsburgh, PA: Psychology Software Tools Inc.

Schouten, B., Gerrits, E., \& Van Hessen, A. (2003). The end of categorical perception as we know it. Speech Communication, 41(1), 71-80. doi:10.1016/s01676393(02)00094-8.

Serniclaes, W. (2010). A review of the evidence in support of allophonic perception in developmental dyslexia. Paper presented at the society for the scientific study of reading (SSSR).

Serniclaes, W. (2011). Allophonic perception in dyslexia: An overview. Escritos de Psicología, 4(2), 25-34. doi:10.5231/psy.writ.2011.26072.

Serniclaes, W., \& Geng, C. (2009). Cross-linguistic trends in the perception of place of articulation in stop consonants: A comparison between Hungarian and French. In F. Pellegrino, E. Marsico, I. Chitoran, \& C. Coupé (Eds.), Approaches to phonological complexity (pp. 241-266). The Hague, The Netherlands: Mouton de Gruyter.

Serniclaes, W., Sprenger-Charolles, L., Carre, R., \& Démonet, J. F. (2001). Perceptual discrimination of speech sounds in developmental dyslexia. Journal of Speech Language and Hearing Research, 44(2), 384-399. doi:10.1044/1092-4388(2001/032).

Serniclaes, W., Van Heghe, S., Mousty, P., Carre, R., \& Sprenger-Charolles, L. (2004). Allophonic mode of speech perception in dyslexia. Journal of Experimental Child Psychology, 87(4), 336-361. doi:10.1016/j.jecp.2004.02.001.

Snowling, M. J. (2000). Dyslexia. Oxford: Blackwell.

Stein, J. (2001). The magnocellular theory of developmental dyslexia. Dyslexia, 7(1), 12-36. doi:10.1002/dys.186.

Stein, J., \& Walsh, V. (1997). To see but not to read; the magnocellular theory of dyslexia. Trends in Neurosciences, 20(4), 147-152. doi:10.1016/S01662236(96)01005-3.

Studdert-Kennedy, M. (2002). Deficits in phoneme awareness do not arise from failures in rapid auditory processing. Reading and Writing, 15, 5-14.

Tallal, P. (1980). Auditory temporal perception, phonics, and reading disabilities in children. Brain and Language, 9(2), 182-198. doi:10.1016/0093934X(80)90139-X. 
Uterwijk, J. (2000). WAIS-III Nederlandstalige bewerking Technische handleiding. [Dutch version: WAIS-III: Manual]. Lisse, The Netherlands: Swets \& Zeitlinger. Van Beinum, F. J., Schwippert, C. E., Been, P. H., Van Leeuwen, T. H., \& Kuijpers, C. T. L. (2005). Development and application of a /bAk/-/dAk/ continuum for testing auditory perception within the Dutch longitudinal dyslexia study. Speech Communication, 47(1/2), 124-142. doi:10.1016/j.specom.2005.04.003.

Van Bon, W. H. J. (1986). Raven's coloured progressive matrices: Nederlandse normen en enige andere uitkomsten van onderzoek. [Raven's coloured progressive matrices: Manual of Dutch norms]. Lisse, The Netherlands: Swets \& Zeitlinger.

Van den Bos, K. P., \& Lutje Spelberg, H. C. (2007). CBEWL. Continu benoemen E' woorden lezen. [Continuous naming and word reading]. Amsterdam, The Netherlands: Boom test uitgevers.

Van den Bos, K. P., Lutje Spelberg, H. C., Scheepstra, A. J. M., \& De Vries, J. R. (1994). De Klepel. [Nonword reading test]. Nijmegen, The Netherlands: Berkhout.

Van den Bos, K. P., Zijlstra, B. J. H., \& Spelberg, H. C. (2002). Life-span data on continuous-naming speeds of numbers, letters, colors, and pictured objects, and wordreading speed. Scientific Studies of Reading, 6(1), 25-49. doi:10.1207/S1532799XSSR0601_02.

Vandermosten, M., Boets, B., Luts, H., Poelmans, H., Golestani, N., Wouters, J., et al. (2010). Adults with dyslexia are impaired in categorizing speech and nonspeech sounds on the basis of temporal cues. Proceedings of the National Academy of Sciences of the United States of America, 107(23), 10389-10394. doi:10.1073/ pnas.0912858107.

Vellutino, F. R., Fletcher, J. M., Snowling, M. J., \& Scanlon, D. M. (2004). Specific reading disability (dyslexia): What have we learned in the past four decades? Journal of Child Psychology and Psychiatry, 45(1), 2-40. doi:10.1046/j.0021-9630.2003.00305.x.

Verhoeven, L. (1995). Drie-Minuten-Toets. [Three-minutes-test]. Arnhem, The Netherlands: Cito.

Verhoeven, L. (2004). ESM Screenings test. [Test for children with specific language impairment]. Arnhem, The Netherlands: Cito.

Vloedgraven, J. M., Keuning, J., \& Verhoeven, L. (2009). Screeningsinstrument beginnende geletterdheid. [Screening instrument for emerging literacy]. Arnhem, The Netherlands: Cito.

Vloedgraven, J. M., \& Verhoeven, L. (2007). Screening of phonological awareness in the early elementary grades: An IRT approach. Annals of Dyslexia, 57(1), 33-50. doi:10.1007/s11881-007-0001-2.

Wagner, R. K., \& Torgesen, J. K. (1987). The nature of phonological processing and its causal role in the acquisition of reading skills. Psychological Bulletin, 101(2), 192-212. doi:10.1037/0033-2909.101.2.192.

Werker, J. F., \& Tees, R. C. (1984). Phonemic and phonetic factors in adult cross-language speech perception. Journal of the Acoustical Society of America, 75(6), 18661878. doi:10.1121/1.390988.

Werker, J. F., \& Tees, R. C. (1987). Speech perception in severely disabled and average reading children. Canadian Journal of Psychology, 41(1), 48-61. doi:10.1037/ h0084150.

White, S., Milne, E., Rosen, S., Hansen, P., Swettenham, J., Frith, U., et al. (2006). The role of sensorimotor impairments in dyslexia: A multiple case study of dyslexic children. Developmental Science, 9(3), 237-255. doi:10.1111/j.1467-7687.2006.00483.x. 